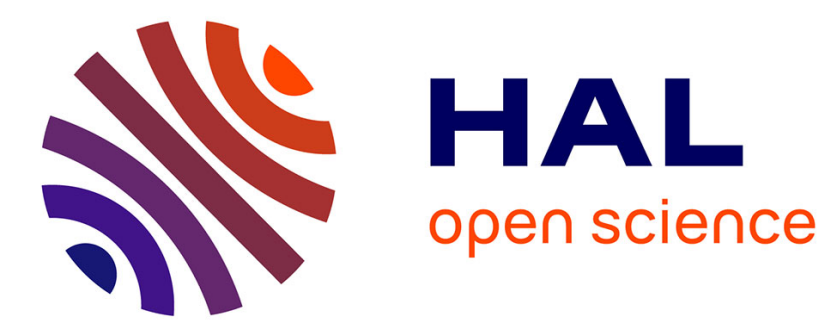

\title{
Microstructure and flow behaviour during backward extrusion of semi-solid 7075 aluminium alloy
}

\author{
Adriana Neag, Véronique Favier, Régis Bigot, Mariana S. Pop
}

\section{To cite this version:}

Adriana Neag, Véronique Favier, Régis Bigot, Mariana S. Pop. Microstructure and flow behaviour during backward extrusion of semi-solid 7075 aluminium alloy. Journal of Materials Processing Technology, 2012, 212 (7), pp.1472-1480. 10.1016/j.jmatprotec.2012.02.003 . hal-02611593

\section{HAL Id: hal-02611593 \\ https://hal.science/hal-02611593}

Submitted on 18 May 2020

HAL is a multi-disciplinary open access archive for the deposit and dissemination of scientific research documents, whether they are published or not. The documents may come from teaching and research institutions in France or abroad, or from public or private research centers.
L'archive ouverte pluridisciplinaire HAL, est destinée au dépôt et à la diffusion de documents scientifiques de niveau recherche, publiés ou non, émanant des établissements d'enseignement et de recherche français ou étrangers, des laboratoires publics ou privés. 


\title{
Microstructure and flow behaviour during backward extrusion of semi-solid 7075 aluminium alloy
}

\author{
Adriana Neag a,* ${ }^{\mathrm{a}}$,éronique Favier ${ }^{\mathrm{b}}$, Régis Bigot ${ }^{\mathrm{c}}$, Mariana Pop ${ }^{\mathrm{a}}$ \\ a Technical University, 103-105 Bwd. Muncii, 400641 Cluj-Napoca, Romania \\ ${ }^{\mathrm{b}}$ Arts et Métiers ParisTech, PIMM UMR CNRS 8006, 151 Bd.de l'Hopital, 75013 Paris, France

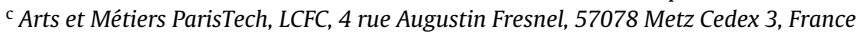

Keywords:

Semi-solid

7075 aluminium alloy

Thixoextrusion

Microstructure

Reheating

\begin{abstract}
A B S T R A C T
The microstructure and flow behaviour during thixo backward extrusion of 7075 aluminium alloy were investigated. Reheating the steel die and the aluminium billet placed into the die at the same time using an induction furnace provides rapidly a very homogeneous microstructure suitable for thixoforming. During thixoextrusion, despite the high solid fraction, the solid globules are weakly connected and slide over each other without any plastic deformation. The flow remains quasi homogeneous resulting in homogeneous induced microstructure of the component.
\end{abstract}

\section{Introduction}

Semi-solid processing by thixoextrusion (one of the thixoforming processes) refers to the shaping of metals by extrusion at a temperature between solidus and liquidus as mentioned in Kirkwood et al.'s (1992) patent. Kapranos et al. (1993) analysed thixoextrusion and found that this technology can be applicable to most engineering alloy families, including aluminium, magnesium, copper and ferrous alloys. Suery (2002) and Atkinson (2005) compared the conventional hot-extrusion processes to thixoextrusion processes of aluminium alloy. They illustrated the most important advantages, such as reduction of the extrusion force and of friction forces between material and tools, higher fluidity of material, longer tool life, high productivity, etc., of the thixoextrusion process. This process required a non-dendritic microstructure made of solid spheroids surrounded by a liquid matrix in order to obtain thixotropic flow behaviour. Several methods can be used to produce this target microstructure. Amongst them, there are the RAP (recrystallisation and partial melting) method patented by Kirkwood et al. (1992) and the SIMA (strain-induced melt activation) method patented by Young et al. (1982). The main difference

\footnotetext{
* Corresponding author at: Technical University, I.P.M. Department (G03), 103-105 Bwd. Muncii, 400641 Cluj-Napoca, Romania. Tel.: +40 744 494695; fax: +40264415054 .

E-mail address: adriana.neag@ipm.utcluj.ro (A. Neag).
}

between these two methods regards the working temperature of the material before reheating. The SIMA route involves hot working at temperatures above the recrystallisation temperature. The RAP route involves working at temperatures below the recrystallisation temperature. In both cases, the billet is reheated into the semi-solid state using either electrical resistance furnace or induction system. In their recent review, Hirt et al. (2009a) mentioned that the heating using classical electric resistance furnace based on radiation/convection heating is cheap but involves long heating time and is a robust process control structure. Induction heating is shorter and provides the possibility of flexible process control. Induction heating systems are mostly used in industrial environments because of their shorter heating time, though Moschini (1992) reported the use of a classical furnace. Many materials were tested using both techniques. Bolouri et al. (2010) and Shang et al. (2010) both used an electrical resistance furnace to reheat aluminium 7075 and 6061 alloys, respectively. Induction systems were used to reheat aluminium-silicon casting alloys (Kapranos et al., 2000), 7075 aluminium alloy (Vaneetveld et al., 2008a) and steels such as $100 \mathrm{Cr} 6$ and $\mathrm{X} 210 \mathrm{CrWl} 2$ (Hirt et al., 2005). When the billet is reheated in an induction furnace, heat losses caused by convection and radiation at the lateral surface of the slug and by heat conduction at the surface bottom occur. Consequently, there is a large difference between the core and the edge temperature. Heating 7075 aluminium alloy, Vaneetveld et al. (2008b) observed that the position of the slug in the inductor did not have any influence on recrystallisation. Using a protective gas leads to large grains 
on the side of the slug revealing a lack of recrystallisation because it raises the heat losses. In order to reduce heat losses, Hirt et al. (2009b) optimised the coil geometry to increase the energy at the edges. In any case, most of thixoforming experiments are carried out with dies at much lower temperatures than the initial slug. They are interesting because they reproduce non-isothermal conditions that can be found in industrial applications. However, they involve solidification phenomena near the die-billet interface because of heat losses. Forn et al. (2010) found that the external quality of an A357 aluminium alloy thixoextruded component is better using colder die temperature (room temperature) because the higher solidification rate raises the pressure applied on the material. Conversely, Vaneetveld et al. (2008a) demonstrated that the optimal external quality for 7075 aluminium alloy component is reached for tool temperatures ranging from $75^{\circ} \mathrm{C}$ to $100^{\circ} \mathrm{C}$. Better understanding of microstructure changes during the forming process is thus required. Clarifying the role of agglomeration-disagglomeration processes from solidification phenomena on the flow behaviour is not possible for non-isothermal processes. Few quasi-isothermal thixoforming trials of steels (Bobzin et al., 2009) and aluminium alloys (Kapranos et al., 2008) exist in literature. They involved ceramic dies but remain a challenging task mainly because of die corrosion and mechanical resistance issues. Compression tests on semi-solid aluminium alloys are more often carried out under quasi-isothermal conditions. Observations of quenched microstructure obtained after deformation help the understanding of the material flow. Kang et al. (1999), who worked on A356 alloy having solid fraction ranging from $50 \%$ to $90 \%$, showed that macro separation appeared between the liquid and the solid but that more homogeneous structure phenomena can be observed with greater compressive velocity. For semi-solid $6061 \mathrm{Al}$ alloys also with high solid fraction, Shang et al. (2010) found that plastic deformation of solid particles and also sliding among the solid particles were dominant deformation mechanisms.

The aim of this paper is to provide such information in the case of quasi-isothermal backward extrusion test of 7075 aluminium alloy in the semi-solid state. The billet was heated inside the extrusion die to avoid the convective and radiation heat losses obtained when the billet is directly heated by induction. The evolution of the formation of the semi-solid microstructure when the billet is placed in a resistance heating furnace or inside a die heated by induction is investigated. It is found that reheating the steel die and the aluminium billet placed into the die at the same time using an induction furnace provides rapidly a very homogeneous microstructure suitable for thixoforming. During thixoextrusion, despite the high solid fraction, the solid globules are weakly connected and slide over each other without any plastic deformation. The flow remains quasi homogeneous resulting in homogeneous induced microstructure so that uniform mechanical properties of the component are expected.

\section{Experimental procedures}

\subsection{Material}

The material used for thixoextrusion was a commercially 7075 aluminium alloy having the following chemical composition $\mathrm{Zn}$ (5.1-6.1)-Mg (2.1-2.9)-Cu (1.2-2)-Cr (0.18-0.28)-Fe (max0.5)-Si (max0.4)-Ti (max0.2) (numbers indicate wt.\%). The material supplier was Euro Alliages/Locatelli, Florange, France. The 7075 wrought aluminium alloy is typically used in aircraft, automotive structural parts and other highly stressed applications where very high strength and good resistance to corrosion are required. The as-received alloy was extruded with an extrusion ratio of 16:1. After extrusion the material was T6 heat treated. The typical

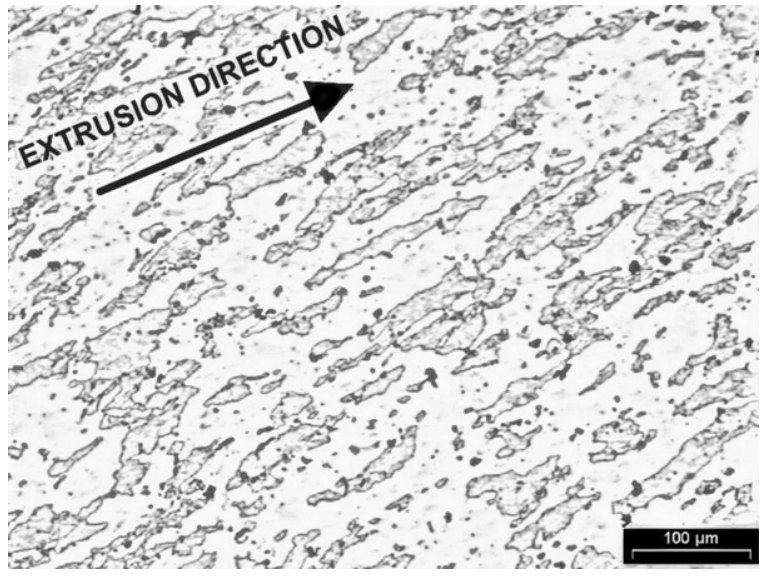

Fig. 1. Typical microstructure of 7075 (T6) extruded aluminium alloy (etched Keller $10 \mathrm{~s})$.

microstructure of this material is shown in Fig. 1. Specimens used to analyse the microstructure were ground with P80-P1200 grit paper, polished using 6-1 micron diamond paste and etched using Keller etch. Optical micrographs revealed microstructures consisting of unrecrystallised primary $\alpha(\mathrm{Al})$ elongated grains, aligned in the extrusion direction, with the grain boundaries well delineated.

\subsection{Semi-solid billet preparation}

A DSC analysis was obtained by courtesy of Mr. Vaneetveld from Liege University (Vaneetveld et al., 2010). Fig. 2 shows the evolution of the solid fraction vs. temperature obtained by calorimetric experiments (heating at $15^{\circ} \mathrm{C} / \mathrm{min}$ ). It reveals low temperature sensitivity for temperatures ranging from $470^{\circ} \mathrm{C}$ to $610^{\circ} \mathrm{C}$ and much higher temperature sensitivity for temperatures ranging from $610^{\circ} \mathrm{C}$ to $650^{\circ} \mathrm{C}$. The working temperature window was chosen equal to $580-610^{\circ} \mathrm{C}$ in order to get a not too high solid fraction (ranging from 0.9 up to 0.7 ) required to get thixotropic behaviour but also a not too low solid fraction to get a reliable process, namely to avoid strong changes of solid fraction due to variation in temperature.

Since the as-received material was cold deformed, the RAP process to get the semi-solid microstructure was investigated. Two different reheating processes are applied: electrical resistance furnace and inductive system. In both cases, the billets are cylindrical specimens with $40 \mathrm{~mm}$ in diameter and $27 \mathrm{~mm}$ height, machined from the extruded bar. These dimensions were chosen to obtain a complete filling of the die after thixoextrusion test. Various heating times to the semi-solid temperature ranging from $5 \mathrm{~min}$

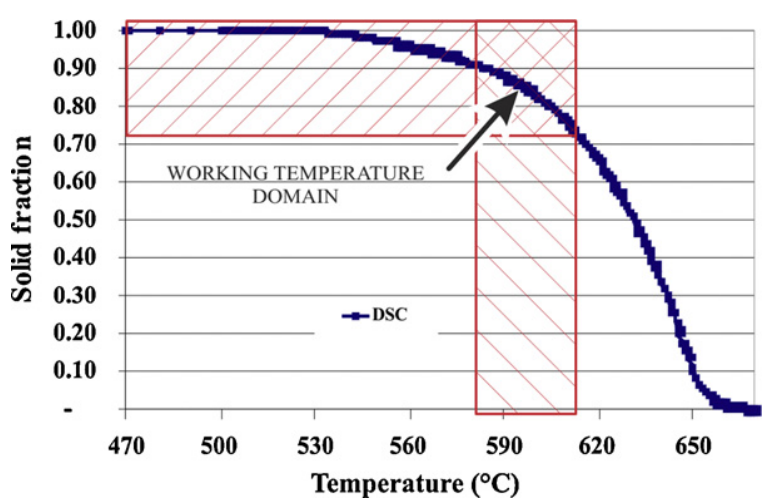

Fig. 2. Solid fraction vs. temperature curves of the 7075 alloy obtained by DSC analysis (heating rate $15^{\circ} \mathrm{C} / \mathrm{min}$; Vaneetveld et al., 2010). 
to $280 \mathrm{~min}$ were investigated. After heating, the billet, alone in the case of resistance heating and inside the dies in the case of inductive heating, was quenched into cold water to "freeze" the microstructure in the semi-solid state. Cross sections of the cylindrical billets were prepared for metallographic observations. They were polished and then etched using the same procedure as for the as-received material. In each case, the whole section was observed but the quantitative analyses were achieved in the centre of the section, unless otherwise stated. The quantitative results were obtained by the image analysis software ImageJ. The mean grain size was measured using a mean linear intercept method. The shape factor was calculated using the equation $F=4 \times \pi \times A / P^{2}$ where $A$ and $P$ are the area and the perimeter of the globule, respectively.

\subsection{Reheating in electrical resistance furnace}

Billets were heated at $580^{\circ} \mathrm{C}$ in an electrical resistance furnace and quenched after holding for $5,15,20,30,60,120,180$ and $240 \mathrm{~min}$. In these cases, thermal radiation generated by the electric resistance heat the billet surface. Heat transfer across the billet occurs by thermal conduction.

\subsection{Reheating by induction}

The reheating was performed using an induction system used in the LCFC laboratory from the "Arts et Métiers ParisTech" Metz (Fig. 3a). In this case, the billet is put inside the die used for thixoforming which has the gauge dimensions of $\varnothing 100 \mathrm{~mm} \times 115 \mathrm{~mm}$ and a cup shape (Fig. $3 b$ ). The dies are made of tool steel $\mathrm{X} 38 \mathrm{CrMoV} 5$. The inductor was designed to perform the reheating of the die containing the slug and to allow the backward extrusion test through the induction coil in order to avoid the transfer of the slug (Fig. 4). The thixoextrusion die containing the initial extruded billet was positioned in the centre of the inductor coil and was placed on a special ceramic support in order to be thermally insulated. The frequency of the electrical generator ranged between 10 and $30 \mathrm{kHz}$. The electrical power was $25 \mathrm{~kW}$. This heating system is controlled by an electronic device which programs the reheating cycles (Fig. 3d). Two "K" type thermocouples were inserted to monitor the temperature evolution: the first one into the centre of the slug (a hole of $2.5 \mathrm{~mm}$ (Fig. 3c) was drilled into the centre of the billet) and the second one was into the die at less than $5 \mathrm{~mm}$ from the slug surface (Fig. $3 \mathrm{~b}$ ). The heating route consisted in 4 successive power stages to ensure a homogeneous temperature in the slug (Fig. 3d). It was obtained by trial and error procedure. Typically, the complete heating cycle lasted $13 \mathrm{~min}$ so that the average heating speed was about $45^{\circ} \mathrm{C} / \mathrm{min}$. Note that in this case, the heat sources are generated by Foucault currents induced by the electromagnetic field within the metal. The induction frequency is about $10-30 \mathrm{kHz}$, so that the penetration depth of the Foucault currents is about $1 \mathrm{~mm}$ from the die surface.

Then, heat transfers by thermal conduction across the die up to the centre of the billet (assuming perfect thermal interface between the die and the billet). Placing the billet into the die avoids the convective and radiation heat losses obtained when the billet is directly heated by induction as Hirt et al. (2009b) had shown.

\subsection{Thixoextrusion tests}

Thixoextrusion tests were carried out on the hydraulic $200 \mathrm{kN}$ press located at the "Arts et Métieres ParisTech" Metz. As mentioned above, the billet was placed into the die. Both were reheated using the induction system (Fig. 4a). They were placed on an Inconel support. A Nefacier $1500^{\odot}$ board was placed between the Inconel support and the table press to reduce heat losses. A tool protector coating (Acheson Pulvegraph D31A) is sprayed after each extrusion test to protect tool surface against wear and chemical attack of aluminium on steel. Upon reaching the desired temperature and holding time, the electric power of the induction system was shut down and the thermocouple which was in the centre of the slug (Fig. 3b) was extracted (Neag et al., 2008). The backward extrusion test was then immediately carried out through the induction coil in order to avoid the transfer of the slug (Fig. 4b and c). Hence, quasiisothermal conditions are obtained. The expected ram speed during the forming was about $6 \mathrm{~mm} / \mathrm{s}$ and the displacement of superior die is limited on the inferior die. After heating and forming, the set was water quenched.

\section{Results and discussion}

\subsection{Semi-solid microstructure before thixoextrusion}

\subsubsection{Reheating by electric resistance furnace}

The microstructure of the material quenched after $5 \mathrm{~min}$ from $580^{\circ} \mathrm{C}$ at the centre part of the billet cross section is shown in Fig. 5a. The grains are elongated and display winding boundaries. After $15-20 \mathrm{~min}$, the grains evolved to a much more equiaxed shape (Fig. 5b and c) but grain boundaries were still winding. After 30 min (Fig. 5d), the microstructure changed to an irregular polygonal structure: grain boundaries are much smoother and are faceted. Some solid particles are surrounded by liquid film (dark phase). The starting microstructure was thus strongly removed. The grain boundaries were gradually penetrated by liquid due to the dissolution of the last solidified phase of low melting temperature like the literature shows (Atkinson and Liu, 2008). Atkinson et al. (2008) indicated that the formation of liquid stimulates the recrystallisation in extruded T6 7075 aluminium alloys. Thanks to the prior deformation and the storage of elastic energy, new more equiaxed grains but having irregular shape replaced the initial elongated grains. The size of the recrystallised grains is highly dispersed ranging from few micrometers to hundred micrometers. Prolonging the holding time (Fig. 5e-h) leads to lubricating more and more grain boundaries, spheroidising solid grains, increasing the number and the size of the intragranular liquid droplets and increasing the mean grain size while reducing the grain size dispersion. These observations are confirmed by more quantitative results. The liquid fraction was found to reach its steady state at $30 \mathrm{~min}$ (Fig. 6a). The value obtained $(\sim 8 \%)$ is in good agreement with DSC analysis results (Fig. 2) and close to the value reported by Atkinson et al. (2008). Prolonging holding times does not change the liquid fraction but changes the microstructure: the number of solid grains decreases while the mean grain size rises up to steady state reached at $120 \mathrm{~min}$ (Fig. 6b). The degree of spheroidisation is found equal to 0.85 . The mean grain size is about $75 \mu \mathrm{m}$.

Clearly, grain growth occurred during electrical resistance reheating. As mentioned by Luo et al. (2009) who analysed the impact of the compression ratio on the microstructure after RAP process on $\mathrm{Mg}$ alloys, grain growth involved two mechanisms: (1) coalescence of solid grains and (2) Ostwald ripening. Concerning (1), low angle/low energy grain boundaries (for which $\gamma_{g b}<\gamma_{s l}$ where $\gamma$ is surface energy and subscripts $g b$ and $s l$ stand for solid/solid and solid/liquid interface, respectively) are not wetted (de Freitas and Ferrante, 2001; Luo et al., 2009). These solid/solid contacts favoring re-welding and coalescence of the grains. As Luo et al. (2009) demonstrated, this mechanism explains why some solid particles (indicated by arrows in Fig. $5 \mathrm{~g}$ ) keep irregular and are faceted despite prolonged holding time. The arrows show migration of some of the grain boundary films. Concerning (2), the finest solid particles melted because of their high curvatures in favor to the larger ones, like in Koke and Modigell (2003), Atkinson and Liu 


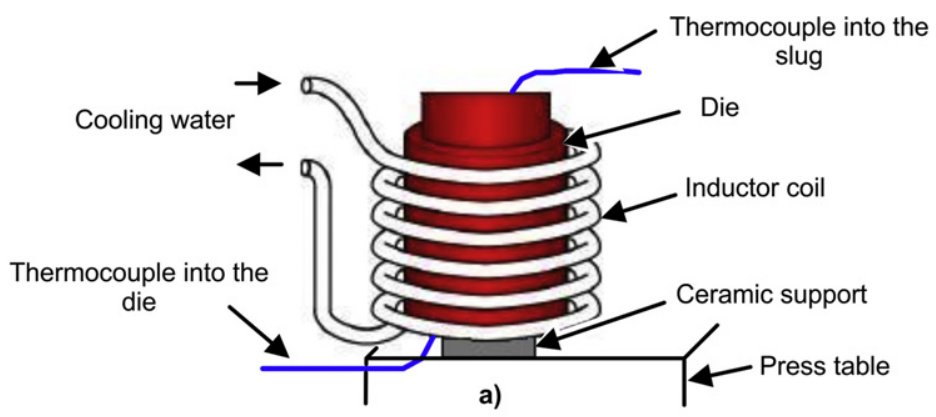

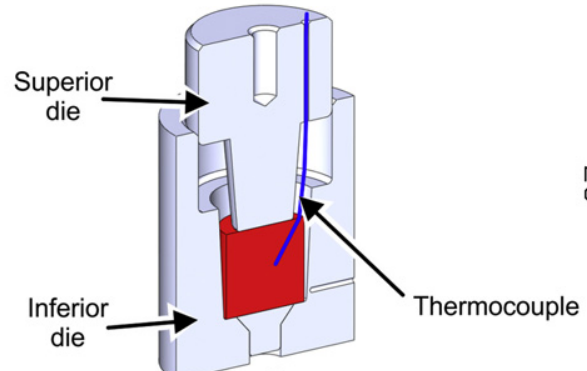

b)

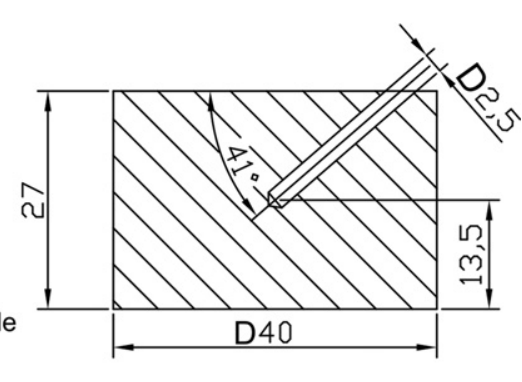

c)

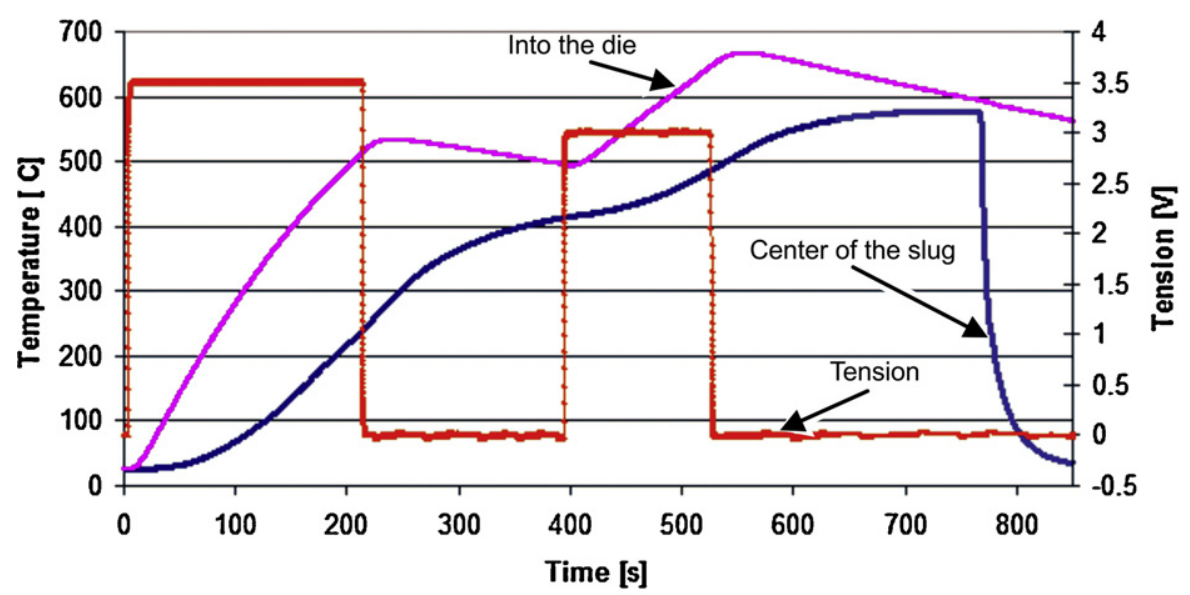

d)

Fig. 3. a) Induction heating process scheme; b) thermocouples positioning scheme; c) dimensions of the billet; d) heating cycle of 7075 aluminium alloy in a die.

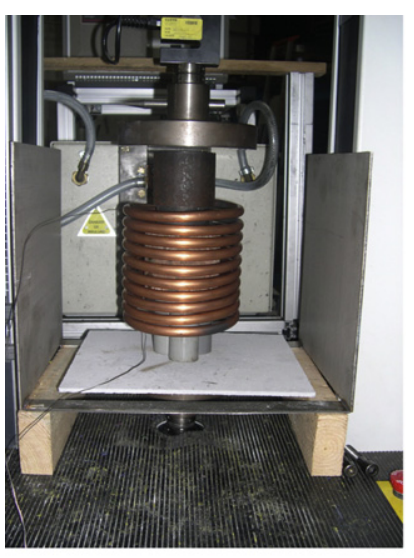

a)

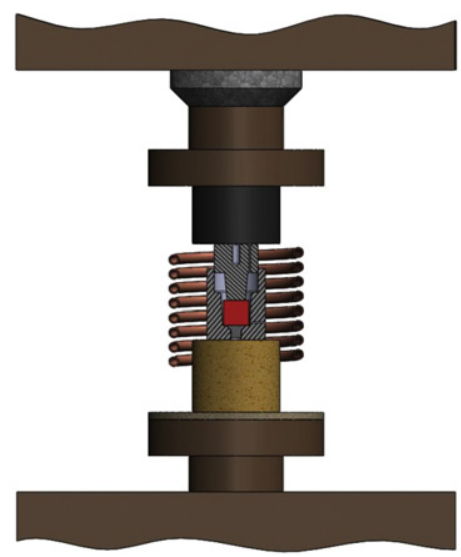

b)

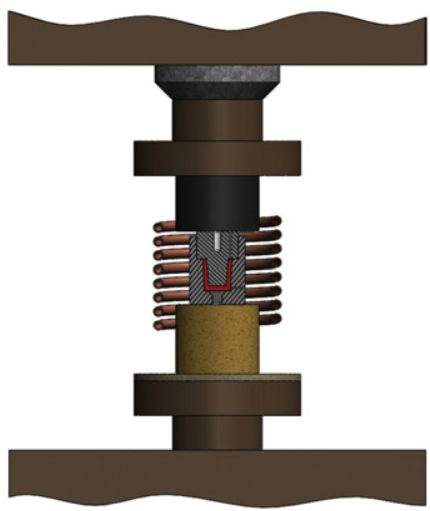

c)

Fig. 4. a) Extrusion device on the press; schematic representation of the thixoextrusion device: b) heating step before thixoextrusion; c) end of thixoextrusion process. 

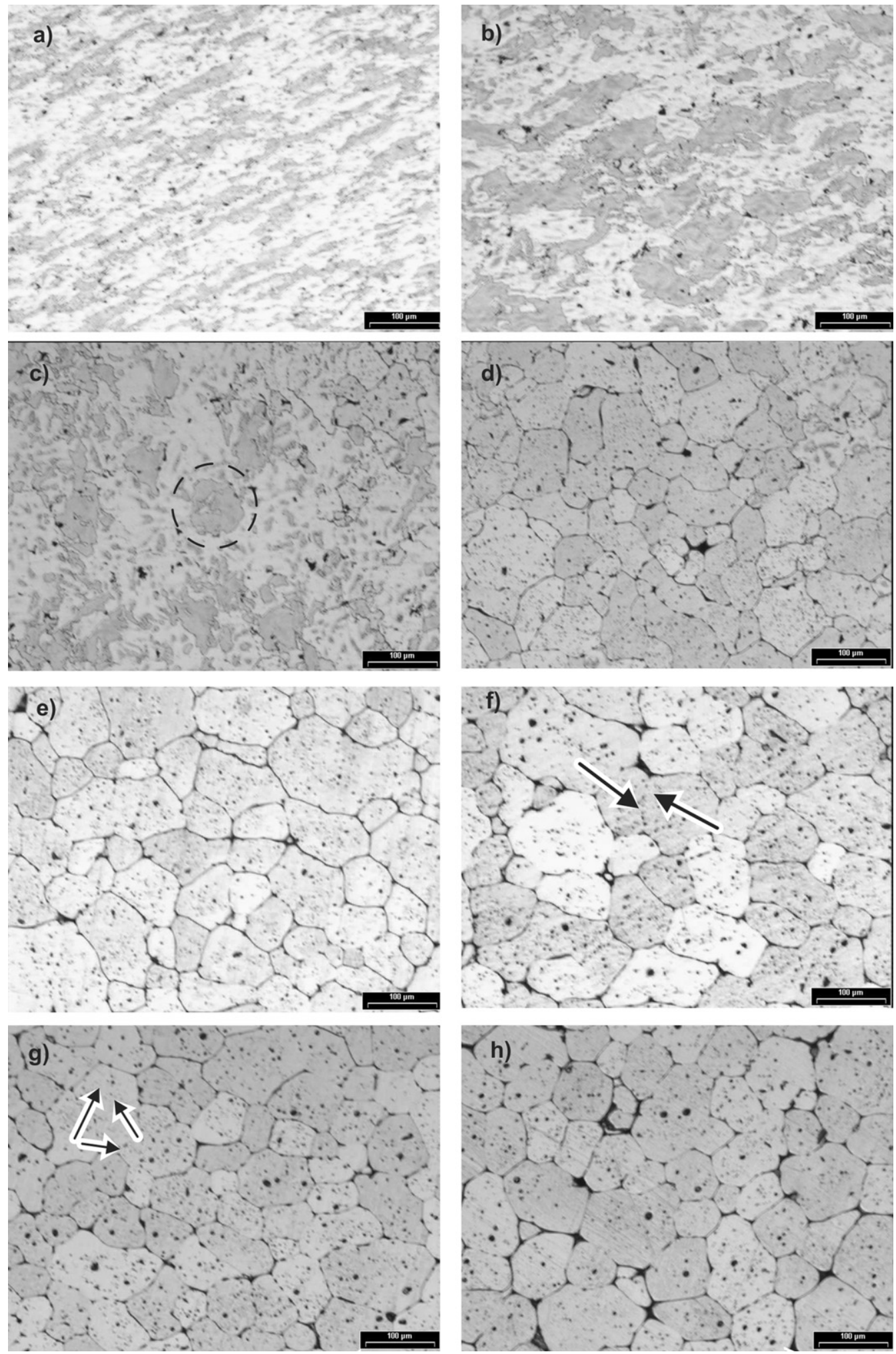

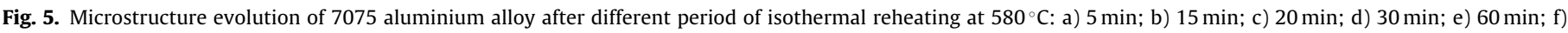
$120 \mathrm{~min}$; g) $180 \mathrm{~min}$; h) $240 \mathrm{~min}$.

(2008) and Luo et al. (2009). Our observations are in good agreement to Tzimas and Zavaliangos (2000), Koke and Modigell (2003), Atkinson and Liu (2008) that clearly shows that this last mechanism is not dominant for the first $240 \mathrm{~min}$ as expected at low liquid fraction. Some liquid droplets are present in the primary phase (Fig. 5). These intragranular liquid droplets possibly originate from the internal inhomogeneity of the primary solid, which is caused by chemical segregation.

With increasing holding time, the number of intergranular droplets decreases and their mean size increases. According to Bolouri et al. (2010), on the one hand, some contiguous intragranular liquid droplets gradually merge into some bigger intragranular 


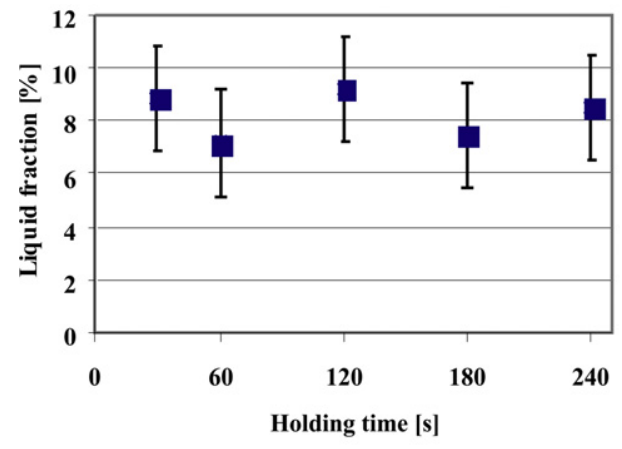

a)

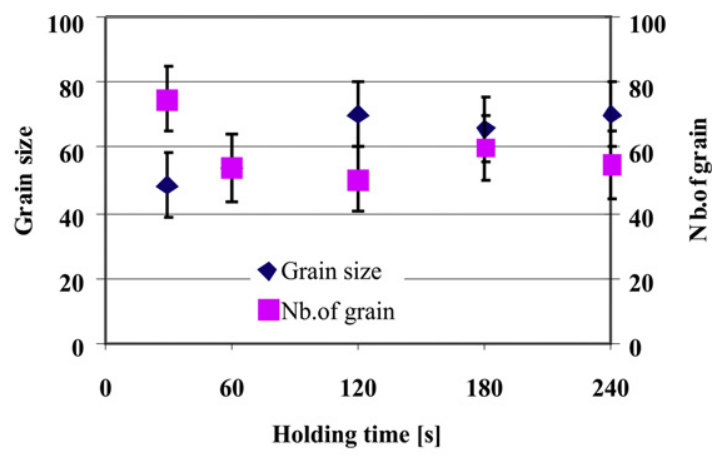

b)

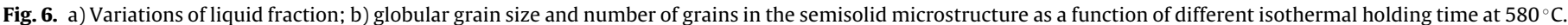

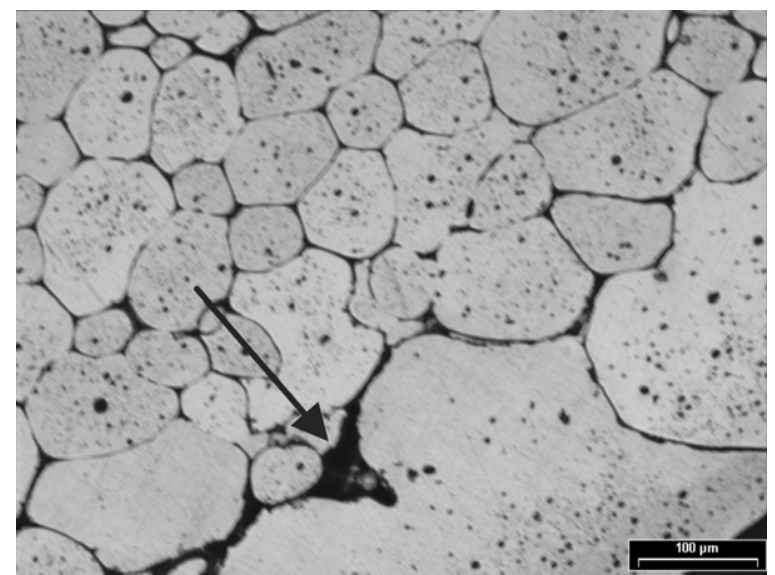

Fig. 7. Microstructure evolution of 7075 aluminium alloy on the slug surface after heating in electrical furnace for $240 \mathrm{~min}$.

droplets by coalescence. On the other hand, Ostwald ripening occurs: small droplets disappear in favor of bigger droplets by diffusion through the solid phase.

As far as microstructure homogeneity is concerned, the solid particles are not uniformly distributed in the slug cross section. The solid grains continue to grow after the first $120 \mathrm{~min}$ at the specimen edge. In addition, Fig. 7 shows evidence of grain coalescence. As a result, interconnected grains form a layer of 300-400 $\mu \mathrm{m}$ thickness at the slug surface.

The presence of large grains was also observed by Wang et al. (2000), Manson-Whitton et al. (2002) and Vaneetveld et al. (2008b). In order to explain this phenomenon, Wang et al. (2000) and Manson-Whitton et al. (2002) mentioned strong coarsening while
Vaneetveld et al. (2008b) suggested that the stored energy within the grains at the surface of the extruded cylinder was not sufficient for recrystallisation. Indeed, friction during extrusion at the solid state induced heat that could decrease the stored energy. The evidence of coalescence (Fig. 7) and the fact that this phenomenon does not exist when the billet is reheated using the induction system, suggest that the large grains observed here result from a prolonged isothermal heating. Further investigations are needed to assess this hypothesis. This large grain layer may impact the flow of the semi-solid during the forming process.

\subsubsection{Reheating of the billet within the die by induction furnace}

Fig. 8 shows the microstructure of 7075 aluminium alloy quenched after $13 \mathrm{~min}$ induction reheating. The temperature at the slug centre during the reheating is given in Fig. 3d. The target temperature was $580^{\circ} \mathrm{C}$. The light primary solid phase and the dark eutectic phase, corresponding to the solid phase and to the liquid phase which are supposed to be present in the semi-solid state, can be clearly seen in the cross and longitudinal section (Fig. 8).

The microstructure contains almost perfectly globular recrystallised grains. The intragranular liquid droplets are homogeneously distributed in the grains and are smaller than in the case of resistance reheating. The microstructure presented in Fig. 9 shows clearly that some small liquid pockets (indicated by A) are entrapped within the spherical solid particles. The particles are surrounded by solid bonds "B" and the not entrapped liquid (indicated by arrow $\mathrm{C}$ ), at $580^{\circ} \mathrm{C}$. The solid fraction is 0.87 in the cross section and 0.81 in the longitudinal section. The average grain size does not exceed $70 \mu \mathrm{m}$. These values are of the same order as in the case of resistance reheating. After induction reheating, it was also observed that the solid particles are much more uniformly distributed on the cross section surface (Fig. 8c). The variation of the shape factor with isothermal holding times is shown in Fig. 10.

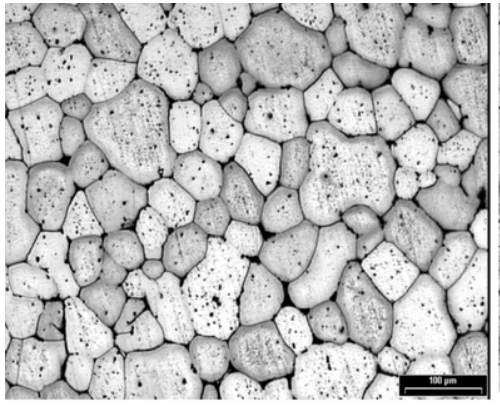

a)

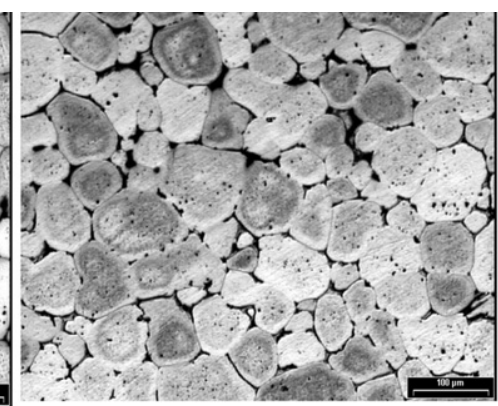

b)

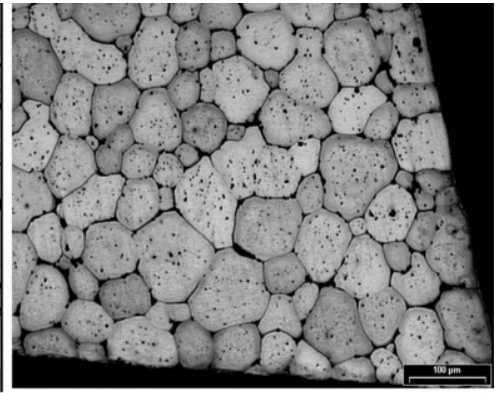

c)

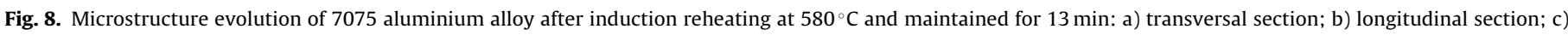
transversal section close to the slug surface. 


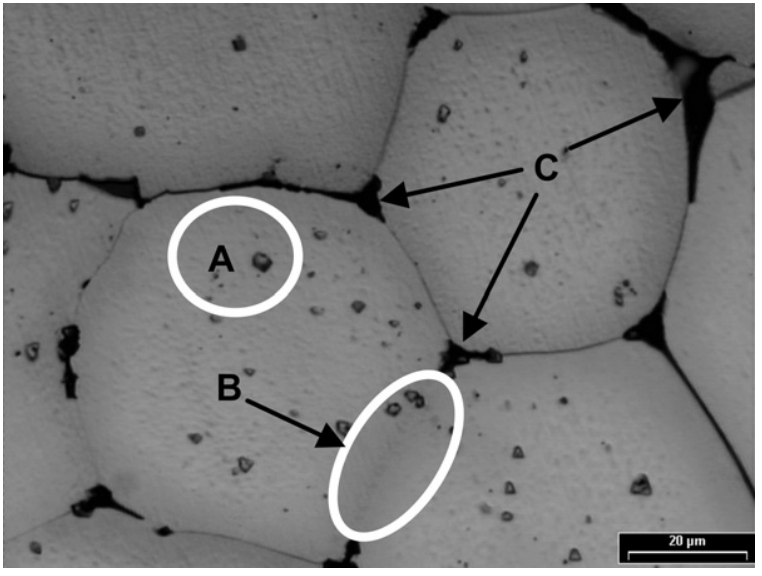

Fig. 9. Microstructure of 7075 alloy after induction reheating at $580{ }^{\circ} \mathrm{C}$ and maintained for $13 \mathrm{~min}$.

The shape factor is strongly dependent on holding time and processes of reheating. It increases up to a steady state value of 0.85 at $60 \mathrm{~min}$ when using the resistance furnace while it increases up to 0.95 after only 13 min when using the induction system. In other words, spheroids are more fully rounded when using the induction system.

Since the low liquid fraction and the quite short holding time involved here, coalescence is the dominant grain coarsening mechanisms as found for resistance reheating. Fig. 9 area B supports this hypothesis. Induction reheating produces quite similar semi-solid microstructure much more rapidly than resistance heating. However, we can notice two major differences. Firstly, the grains are more spherical in shape: they are still faceted but do not display sharp corners. Secondly, the microstructure is more homogeneous in the slug cross section. Induction heating produces very much higher power densities than thermal radiation. This allows short interaction time to reach the required temperature while preventing from grain growth. Recrystallisation occurred entirely and homogeneous microstructure with spherical grains is obtained. This microstructure is suitable for thixoforming and short heating time is obviously very interesting for industrial application. Microstructure changes during thixoforming were investigated and results are presented in the next section.

\subsection{Thixoextrusion test: load and induced microstructure}

Fig. 11 shows the load-displacement responses for three temperatures: $602{ }^{\circ} \mathrm{C}, 609^{\circ} \mathrm{C}$ and $617^{\circ} \mathrm{C}$. These temperatures correspond to solid fraction of $0.82,0.77$ and 0.69 , respectively (Fig. 2).

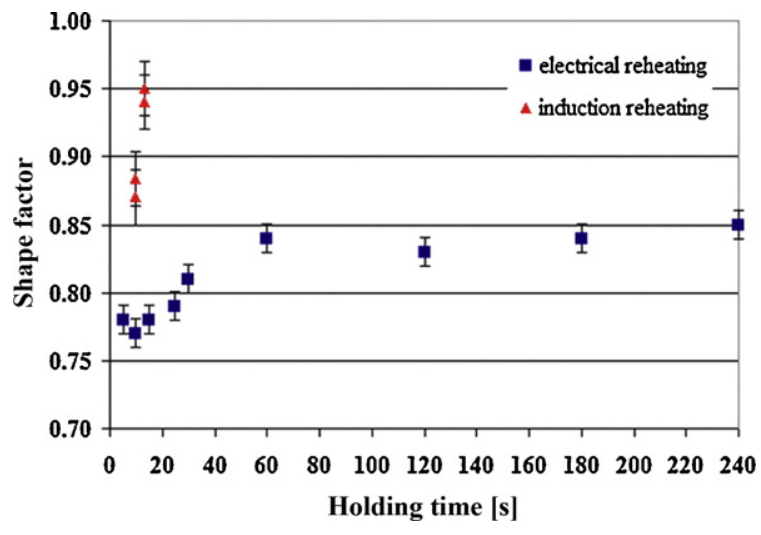

Fig. 10. Shape factor vs. time.

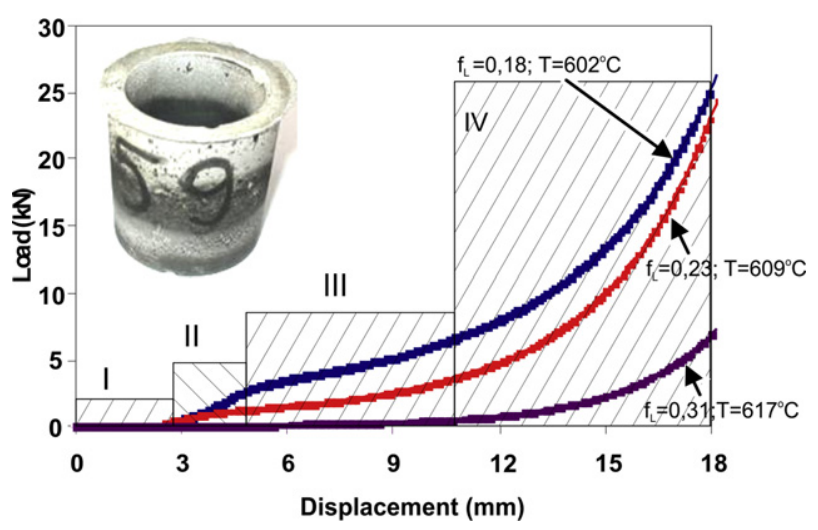

Fig. 11. Load-displacement responses during thixoextrusion at three temperatures.

The load ranged from 0 to $30 \mathrm{kN}$. The load-displacement curve can be divided into four stages. The first stage associated with zero force corresponds to the motion of the upper ram until it touches the upper part of the die. Then, the slug is compressed and fills the lower part of the component (stage II). The stages III and IV are related to the backward extrusion and the filling of the cup. During this filling, the contact area between the slug and the die increases. As a result, the load rises due to the increasing friction. Note that complete die filling was obtained.

The load clearly decreased with decreasing solid fraction. This result is expected and consistent with literature data for any semi-solids such as Sn-Pb alloys shown by Fan and Chen (2002), aluminium alloys by Kang et al. (1999) and Liu et al. (2003), or steels by Shimahara et al. (2006). At $f_{s}=0.69$, the material does not display sufficient resistance to be measured by the load cell until the stage IV. It was difficult to remove the cup from the upper part of the die due to a strong adherence. The cup was found with a very bad surface quality while the cup displayed a much better surface quality for 0.77 and 0.82 solid fraction. As $f_{s}=0.77$ appears as a good compromise to get lower load and a good surface quality, we analysed the microstructure of the component obtained after forming and quenching.

The extruded cup was sectioned along the vertical axis for metallographic observations. No appreciable difference is observed between the seven microstructures (Fig. 12). A globular structure of the primary Al phase, similar to that found in Fig. 8 obtained after reheating, is observed in the whole section of the cup. More quantitative results show that the solid fraction is about 0.8 at the bottom of the cup and slowly decreases up to 0.74 at the upper part of the cup. These results reveal the presence of (1) a slight segregation of the liquid during the forming process and (2) sliding among solid particles without any plastic deformation.

In these experiments, despite the high solid fraction (0.75-0.8), the solid grains are very weakly connected and most of grain boundaries are wetted by a thin liquid film. As a result, the flow is mainly driven by the liquid and remains quasi homogeneous. Under these quasi isothermal conditions, the slight segregation phenomenon is attributed to the geometry of the cup. In the course of the filling, the flow front surface area increases with increasing diameter of the cup. Such an increase is easily accommodated by the liquid phase which is much more fluid whereas the solid particles could interfere with each other and slow down in their movement (Hirt et al., 2009b). This segregation phenomenon remains small because of the small amount of liquid. As mentioned in Kang et al. (1999) and Becker et al. (2010) for steels and aluminium alloys, the solid/liquid phase macro separation seems to require a high enough amount of liquid, or more precisely, a high enough amount of free liquid. Then, a preferred flow path develops dominated by the free liquid. As a result, a critical temperature above which the flow is 


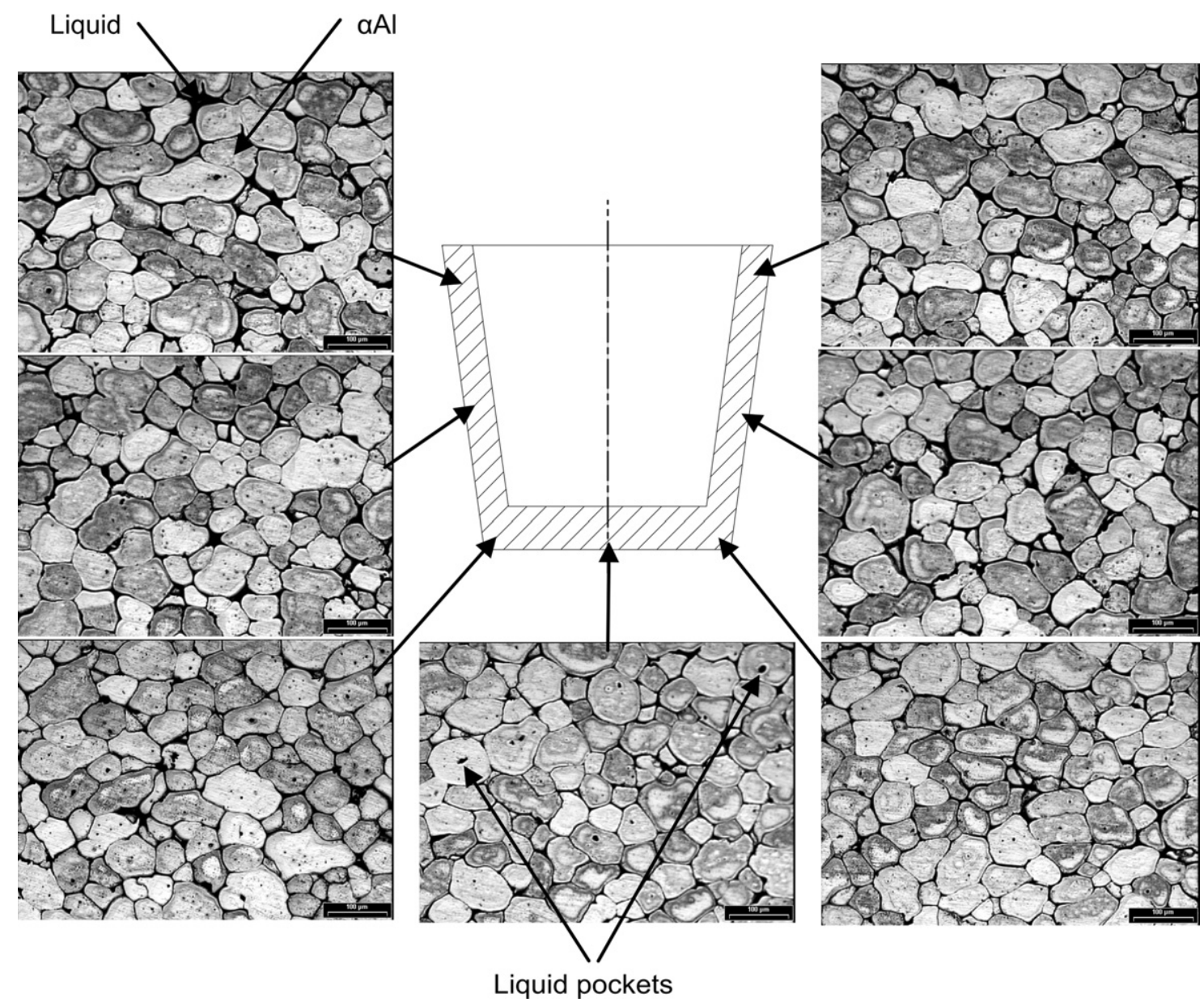

Fig. 12. Quenched microstructure of the thixoextruded cup $\left(T=609^{\circ} \mathrm{C}, f_{l \mathrm{DSC}}=25 \%\right)$.

heterogeneous seems to exist. Suery and Flemings (1982), ValetteBrives (1992) and Rouff (2003) suggested the existence of a critical strain rate above which homogeneous flow was observed. Li et al. (2005), who worked on stainless steel, mentioned that the critical temperature does not depend on strain and strain rate. Our experiments displaying very slight segregation phenomena involved small strain rates - about $1 \mathrm{~s}^{-1}$ - and low semi-solid slug temperature (Neag et al., 2008). These results are arguments to claim that the slug temperature plays a key role on liquid phase segregation phenomena. Geometry and temperature of the dies also affects macro segregation as Kopp et al. (2004), Li et al. (2005) and Becker et al. (2010) found, but probably to a lower extent.

\section{Conclusions}

The present paper reported for 7075 aluminium alloy (1) the semi-solid microstructure obtained by two reheating systems and (2) the microstructure and flow behaviour during thixoextrusion tests. Results show that:

1. Reheating an extruded aluminium billet inside the steel die by an induction furnace avoids heat losses and too strong coarsening of grains. It rapidly provides a homogenous microstructure made of globular solid grains surrounded by thin liquid film, which is suitable for thixoforming.

2. During the quasi isothermal thixo backward extrusion tests, the flow remains quasi homogeneous. Deformation takes place by rearrangement of the globules with respect to each other without any plastic deformation. Despite the high solid fraction $(>0.75)$, the solid particles are weakly connected.

3. The slight liquid phase macro segregation phenomenon observed for quasi-isothermal thixo backward extrusion test at temperature lower than $609^{\circ} \mathrm{C}$ is attributed to the geometry of the die. Increasing the slug temperature (and so the thixoextrusion test) at temperatures higher than $609^{\circ} \mathrm{C}$ promotes much stronger macro segregation resulting in bad component in shape and in surface state.

\section{Acknowledgements}

This paper was supported by the project "Develop and support multidisciplinary postdoctoral programs in primordial technical areas of national strategy of the research-developmentinnovation" 4D-POSTDOC, contract nr. POSDRU/89/1.5/S/52603, project co-funded from European Social Fund through Sectorial Operational Program Human Resources 2007-2013 and by the PAI Brâncuşi Program.

\section{References}

Atkinson, H.V., 2005. Modelling the semisolid processing of metallic alloys. Prog. Mater. Sci. 50, 341-412.

Atkinson, H.V., Burke, K., Vaneetveld, G., 2008. Recrystalisation in the semi-solid state in 7075 aluminum alloy. Mater. Sci. Eng. A 490, 266-276.

Atkinson, H.V., Liu, D., 2008. Microstructural coarsening of semi-solid aluminium alloys. Mater. Sci. Eng. A 496, 439-446.

Becker, E., Favier, V., Bigot, R., Cézard, P., Langlois, L., 2010. Impact of experimental conditions on material response during forming of steel in semi-solid state. J. Mater. Process. Technol. 210, 1482-1492. 
Bobzin, K., Lugsheider, E., Schneider, J.M., Telle, R., Immich, P., Hajas, D., Münstermann, S., 2009. Tool technologies for forming of semi-solid metals. In: Hirt, G., Kopp, R. (Eds.), Thixoforming: Semi-solid Metal Processing. Wiley-VCH Verlag GmbH \& Co., pp. 241-308 (Ch. 8)

Bolouri, A., Shahmiri, M., Cheshmeh, E.N.H., 2010. Microstructural evolution during semisolid state strain induced melt activation process of aluminium 7075 alloy. Trans. Nonferrous Met. Soc. China 20, 1663-1671.

Fan, Z., Chen, J.Y., 2002. Modeling of rheological behavior of semisolid metal slurries. Part 2. Steady state behavior. Mater. Sci. Technol. 18 (3), 243-249.

Forn, A., Vaneetveld, G., Pierret, J.C., Menargues, S., Baile, M.T., Campillo, M., Rassili, A., 2010. Thixoextrusion of A357 aluminium alloy. Trans. Nonferrous Met. Soc. China 20 (3), s1005-s1009.

de Freitas, E.R., Ferrante, M., 2001. Rheological behaviour and deformation characteristics of a commercial and a laboratory-cast $\mathrm{Al}-4 \% \mathrm{Cu}$ alloy in the semi-solid state. Acta Mater. 49, 3839-3847.

Hirt, G., Shimahara, H., Seidl, I., Kuthe, F., Abel, D., Schonbohm, A., 2005. Semisolid forging of $100 \mathrm{Cr} 6$ and X210CrW12 steel. CIRP Ann. Manuf. Technol. 54 (1), 257-260.

Hirt, G., Khizhnakova, L., Baadjou, R., Knauf, F., Kopp, R., 2009a. Semi-solid forging aluminium and steel. Introduction and overview. In: Hirt, G., Kopp, R. (Eds.), Thixoforming: Semi-solid Metal Processing. Wiley-VCH Verlag GmbH \& Co., pp. $1-27$.

Hirt, G., Baadjou, R., Knauf, F., Seidl, I., Shimahara, H., Abel, D., Kopp, R., Gasper, R., Schönbohm, A., 2009b. Thixoforging and rheoforging of steel and aluminium alloys. In: Hirt, G., Kopp, R. (Eds.), Thixoforming: Semi-solid Metal Processing. Wiley-VCH Verlag GmbH \& Co., pp. 369-409 (Ch. 10).

Kang, C.G., Choi, J.S., Kim, K.H., 1999. The effect of strain rate on macroscopic behavior in the compression forming of semi-solid aluminum alloy. J. Mater. Process. Technol. 88, 159-168.

Kapranos, P., Kirkwood, D.H., Sellars, C.M., 1993. Semi-solid processing of tool steel. J. Phys. IV (3), 835-840.

Kapranos, P., Ward, P.J., Atkinson, H.V., Kirkwood, D.H., 2000. Near net shaping by semi-solid metal processing. Mater. Des. 21, 387-394.

Kapranos, P., Haga, T., Pola, A., Azpilgain, Z., Urtado, I., 2008. Thixo-extrusion of 5182 aluminium alloy. Solid State Phenom. 141-143, 115-120.

Kirkwood, D.H., Sellars, C.M., Elias-Boyed, L.G., 1992. Thixotropic materials. European Patent 0305375, B1.

Koke, J., Modigell, M., 2003. Flow behaviour of semi-solid metal alloys. J. NonNewtonian Fluid Mech. 112 (2-3), 141-160.

Kopp, R., Shimahara, H., Schneider, J.M., Kurapov, D., Telle, R., Munstermann, S., Lugscheider, E., Bobzin, K., Maes, M., 2004. Characterization of steel thixoforming tool materials by high temperature compression tests. Steel Res. Int. 75 (8-9), 569-576.

Li, J.-Y., Sugiyama, S., Yanagimoto, J., 2005. Microstructural evolution and flow stress of semi-solid type 304 stainless steel. J. Mater. Process. Technol. 161 (3), 396-406.
Liu, T.Y., Atkinson, H.V., Kapranos, P., Kirkwood, D.H., Hogg, S.C., 2003. Rapid compression of aluminum alloys and its relationship to thixoformability. Metal. Mater. Trans. A 34 (7), 1545-1554.

Luo, S., Chena, Q., Zhao, Z., 2009. An investigation of microstructure evolution of RAP processed ZK60 magnesium alloy. Mater. Sci. Eng. A 501, 146-152.

Manson-Whitton, E.D., Stone, I.C., Jones, J.R., Grant, P.S., Cantor, B., 2002. Acta Mater 50, 2517-2535.

Moschini, R., 1992. Manufacture of automotive components by semi-liquid forming processes. In: Proceedings of the 2nd International Conference on Semi-Solid Processing of Alloys and Composites, Boston, USA, MIT Publ., Cambridge, MA USA, pp. 144-158.

Neag, A., Favier, V., Bigot, R., Frunză, D., 2008. Study on thixo-extrusion of semi-solid aluminium. In: Proceeding of the 10th International Conference on SemiSolid Processing of Alloys and Composites, Trans Tech Publications, Aachen, Germany/Liege, Belgium, pp. 659-664.

Rouff, C., 2003. Contribution à la caractérisation et à la modélisation du comportement d'un acier à l'état semi-solide. Application au thixoforgeage, Thesis, ENSAM, Metz, France.

Suery, M., Flemings, M.C., 1982. Effect of strain rate on deformation behaviour of semi-solid dendritic alloys. Metal. Trans. A 13, 1809-1819.

Suery, M., 2002. Mise en forme des alliages métalliques à l'état semi-solide. Traité MIM Mecanique et Ingénierie des Matériaux, Ed. Lavoisier.

Shang, S.-Z., Lu, G.-M., Tang, X.-L., Zhao, Z.-X., Wu, C.-M., 2010. Deformation mechanism and forming property of Al6061 alloys during compression in semi-solid state. Trans. Nonferrous Met. Soc. China 20, 1725-1730.

Shimahara, H., Baadjou, R., Kopp, R., Hirt, G., 2006. Investigation of flow behaviour and microstructure on X210CrW12 steel in semi-solid state. Solid State Phenom. $116-117,189-192$.

Valette-Brives, E., 1992. Mise en forme d'aciers à l'état semi-solide: étude expérimentale et modélisation. Thesis, Ecole Nationale Supérieure de Mines de Paris/Ecole Nationale Supérieure de Mines de Saint-Etienne, France.

Vaneetveld, G., Rassili, A., Pierret, J.-C., Lecomte-Beckers, J., 2008a. Extrusion tests of 7075 aluminium alloy at high solid fraction. Int. J. Mater. Forming 1 (Suppl. 1) 1019-1022.

Vaneetveld, G., Rassili, A., Atkinson, H.V., 2008b. Influence of parameters during induction heating cycle of 7075 aluminium alloys with RAP process. Solid State Phenom. 141-143, 719-724.

Vaneetveld, G., Rassili, A., Pierret, J.-C., Lecomte-Beckers, J., 2010. Conception of tooling adapted to thixoforging high solid fraction hot-crack-sensitive aluminium alloys. Trans. Nonferrous Met. Soc. China 20,1712-1718.

Tzimas, E., Zavaliangos, A., 2000. Evolution of near-equiaxed microstructure in the semisolid state. Mater. Sci. Eng. A 289, 228-240.

Wang, P.-J., Lee, T.-A., Tu, T.-N., Huang, C.-T., 2000. Improvement of grain coarsening on the surface of extra-low carbon wire rods. China Steel Tech. Report 23, 75-77.

Young, K.P., Kyonka, C.P., Courtois, J.A., 1982. Fine grained metal composition. US Patent 4,415,374, 30 March. 